\title{
ORIGEM DAS CACHOEIRAS DA BACIA DO ALTO PARANA**
}

\author{
SAMIR FELICIO BARCHA E FAHAD MOYSÉS ARID**
}

\begin{abstract}
Sculptured in the northern part of the Parana Basin, specially in its basaltic rocks, the Rio Grande presents majestic falls and rapids, which are singular features of its physiography on its lower course.

In this work were studied Marimbondo, Água Vermelha, Mutuca and Onça falls.

Morphologically those falls have the same characteristics: the river is wide and shallow before them, and narrow and deep after them; they are constituted by complex groups of falls and rapids, which present a maximum lenght of $4 \mathrm{~km}$ and a maximum height of $30 \mathrm{~m}$.

Geologically, the falls are always associated with the basaltic rocks of Serra Geral Formation, being present also, although irregularly, lens of intra-trapiano sandstone and basaltic breccia.

Statistical measures of directions of joints reveal the existence of preferential systems of rock fractures, specially around N-S, E-W, N30E and N30W.

By this study, we may conclude: (1) all the falls have identical features and behavior, suggesting common processes in their origin and development; (2) there is a marked structural control of the falls and rapids and of all the involved drainage; (3) the origin and evolution of the falls are directly connected to the joint systems and also to the textural differences present in the rocks; (4) little faults, although not observed in the field, but indirectly inferred, could be another factor also responsible by the origin of those features; (5) comparative and correlative studies with other falls and rapids present in the Alto Paraná Basin, suggest identical processes on the origin and development of all falls of that basin.
\end{abstract}

INTRODUÇÃo O Rio Grande está situado na divisa norte de São Paulo com Minas Gerais e constitui o principal componente da bacia do alto Paraná. Esculpido na porção norte da bacia sedimentar do Paraná, especialmente em rochas basálticas, o rio apresenta imponentes cachoeiras e corredeiras, que constituem uma constante da fisionomia de todo seu curso médio e inferior. As cachoeiras do Marimbondo, da Água Vermelha, Mutuca e da Onça, aí presentes, foram estudadas com o propósito de se estabelecer o mecanismo de sua origem e evolução, e na tentativa de se obter um modelo geral para a origem e evolução das quedas presentes na bacia do alto Paraná. Em todas elas as mesmas feições mor. fológicas estão presentes, ocorrendo sempre associação com os basaltos da Formação Serra Geral. Comparecem irregularmente lentes de arenito intratrapiano e brechas de basalto, presentes em outros locais da bacia. O levantamento estatístico das direções dos planos de fraturas do basalto foi realizado nas áreas dessas cachoeiras, com o intuito de se relacionar a direção dos principais sistemas dessas fraturas com a direção das quedas, das corredeiras e com as mudanças locais de direção do curso do rio.

$O$ estudo dessas quedas oferece ainda contribuição para o restabelecimento do quadro paleo-hidrográfico da bacia e suas relações com o atual estágio de evolução do Rio Grande.

As primeiras observações sobre o Rio Grande devem-se a Pacheco (1913), ao tempo da antiga Comissão Geographica e Geológica do Estado de São Paulo. O autor chamou a atenção para o papel desempenhado pelos sistemas de juntas do basalto, observadas nos rios Grande e Turvo, nas feições principais de seus saltos e cachoeiras. Destacou a presença

* Com auxílio da Fundação de Amparo à Pesquisa do Estado de São Paulo

**Departamento de Geociências e Química, Faculdade de Filosofia, Ciências e Letras de São José do Rio Preto, Caixa Postal 136, Estado de São Paulo, Brasil 
de juntas fortemente inclinadas e também juntas separando a rocha em massas lenticulares, realçadas pelas águas de infiltração.

Deve-se a Washburne (1930) a primeira tentativa de se estabelecerem as prováveis causas para as quedas da bacia do Paraná, admitindo-se a interferência de estruturas de deformação do tipo monoclinal. Tais estruturas, segundo o autor, resultariam da deposição original da lava sobre irregularidades do solo, de irregularidades da superficie da lava, ou, então, de subsequientes deformações. A essas estruturas foram atribuídos também os saltos de Urubupungá e Guaíra.

Lamego (1935) chamou a atenção para intercalaçóes diabásicas no arenito Botucatu, as quais, segundo supôs, responderiam pelas cachoeiras escalonadas do rio, especialmente a Cachoeira da Onça, Agua Vermelha e Marimbondo.

Deve-se a Arid e Landim (1967) estudo detalhado da área da Cachoeira do Marimbondo, chamando a atenção para o controle estrutural da drenagem e para a marcante influência das fraturas do basal to na origem e evolução das quedas.

Aspectos geológicos do vale do Rio Grande $O$ traçado da geologia geral do vale do Rio Grande mostra uma setorização natural ao longo da bacia, determinada pela distribuição espacial da litologia (Fig. 1). No presente trabalho, foram considerados apenas os aspectos geológicos dos cursos médio e inferior, mais diretamente relacionados às quedas estudadas. No curso médio, predominam os basaltitos da Formação Serra Geral e, subsidiariamente, sedimentitos das Formações Pirambóia e Botucatu. Os basaltitos distribuem-se desde as proximidades de Rifaina até a confluência do Rio Pardo. No curso inferior, dominam os arenitos da Formação Bauru. Os basaltos são restritos ao leito, às margens do Rio Grande e aos cursos inferiores de seus tributários, onde o capeamento sedimentar já foi removido. Em todo o lado mineiro, na margem direita do Rio Grande, está presente a Formação Rio Grande (Arid e Barcha, 1971), em extensa faixa, de largura e espessura variáveis.

FORMAÇÃO SERRA GERAL (Ke) Os basaltos ocorrem na forma de derrames. Na parte basal de cada derrame, a rocha é microcristalina, de cor preta, granulação fina e intensamente fraturada, vertical e horizontalmente. $O$ topo dos derrames tem cores cinzenta ou avermelhada e, quase sempre, está mais alterado que a base. As amígdalas estão preenchidas por cristais de quartzo, calcita ou zeólitas, isoladamente ou misturados.

Associadas aos derrames, no contato entre a fase amigdalóide do derrame inferior e a microcristalina da base do derrame superior, ocorrem lentes de arenito Botucatu, intratrapiano e brechas de basalto. São de pequena extensão, não ultrapassando algumas dezenas de metros, nos locais observados e com espessura variável de até $50 \mathrm{~cm}$. Essas lentes são constituídas de arenito fino a muito fino, avermelhado, bastante silicificado e extremamente duro. São bem evidentes na Cachoeira do Marimbondo, nas proximidades de Ṕaulo de Faria e na Cachoeira dos Índios. Muitas vezes, esse arenito forma verdadeiros diques anastomosados, cuja origem está relacionada ao preenchimento de antigas fraturas presentes no basalto, na época de sua deposição (Arid e Landim, 1967).

Ocorrem também brechas de basalto, associadas ou não às lentes de arenito. Tais brechas são constituídas por fragmentos de basalto amigdalóide, cimentados por matriz arenosa de granulação muito fina e dura. São também lenticulares, de espessura variável, podendo atingir pouco mais de $1 \mathrm{~m}$. Podem ser observadas no Canal do Ferrador e no Braço Morto (Cachoeira do Marimbondo), com cota igual a $390 \mathrm{~m}$, em Paulo de Faria (cota de $380 \mathrm{~m}$ ) e na Cachoeira dos Indios (cota de $350 \mathrm{~m}$ ). Os fatos sugerem que tais ocorrências pertencem ao mesmo nível geológico, indicando, pois, mergulho regional para juzante, oeste, conforme já estabelecido por outros autores (Frangipani, 1961-62). 


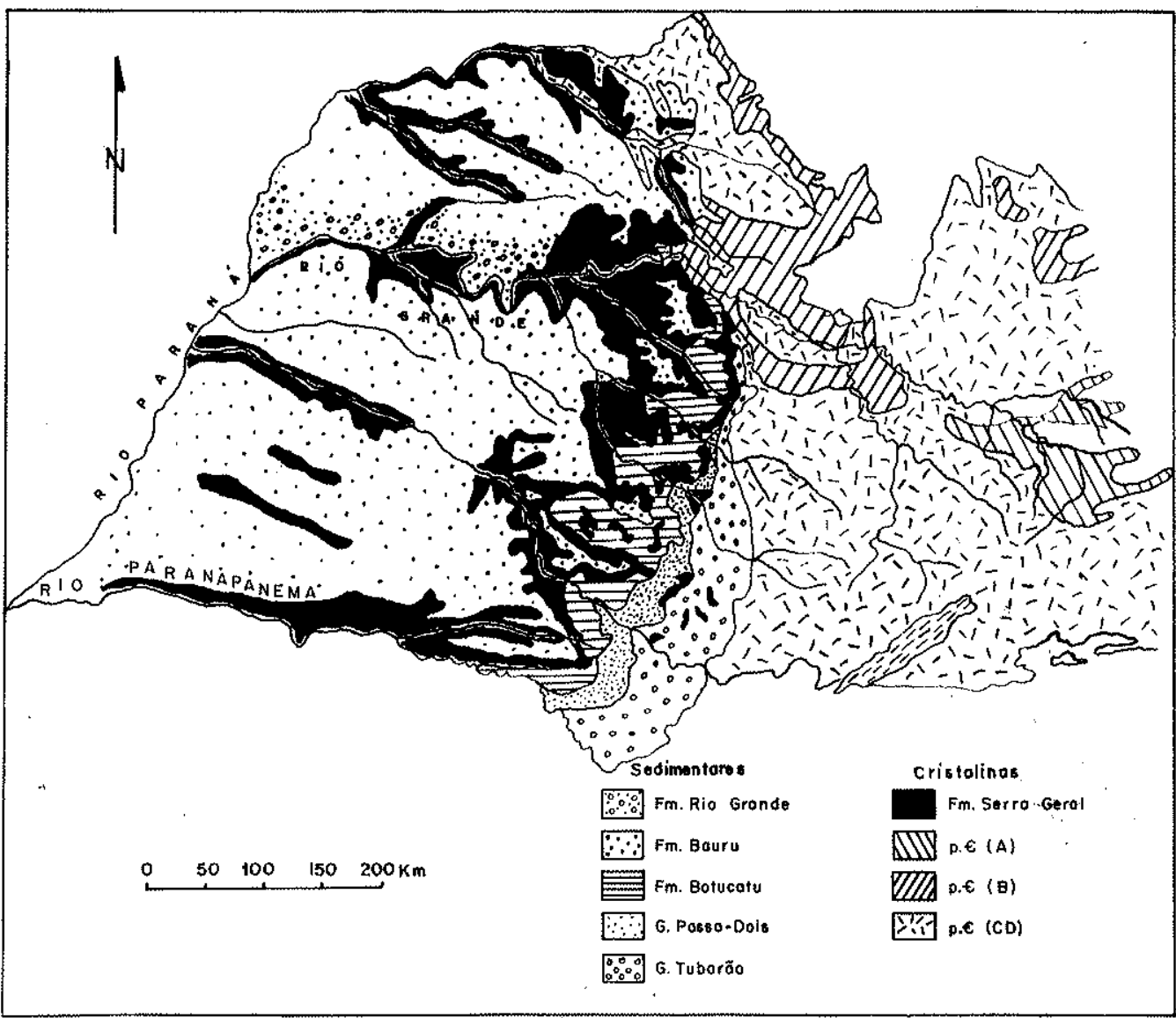

Figura 1 - Geologia da bacia do Rio Grande (baseada no mapa geológico do Brasil, 1960)

Segundo Arid e Landim ( $o p$. cit.), essas brechas de basalto originaram-se da fragmentação da porção amigdaloidal do derrame pela erosão, seguida de preenchimento dos espaços, entre os blocos angulosos de basalto amigdalóide, por areias eólicas. $\mathrm{O}$ fato de tais blocos apresentarem pronunciada angulosidade indica que essa fragmentação ocorreu no mesmo local, ou próximo do ponto onde hoje se localizam as brechas. Quando do novo derrame, as areias teriam sido cimentadas e endurecidas por águas silicosas dele provenientes, formando então as brechas.

A melhor exposição de basalto encontra-se ao longo da Cachoeira do Marimbondo. Em razão da profunda incisão produzida pelo rio nessa área, podem ser constatados três derrames distintos, levando-se em conta o contato entre suas porções microcristalina e amigdalóide, geralmente com as lentes intratrapianas presentes, como indicador da separação entre eles. Tais derrames estão sempre associados com os terraços mais próximos do rio, sendo os mais jovens periodicamente inundados pelas águas, nas épocas mais chuvosas.

FORMAÇÃO BAURU (Kn) Dominando todo o vale, na margem esquerda (ou paulista), ocorrem rochas da Formação Bauru, representando o mais expressivo conjunto de rochas do curso inferior. Do lado mineiro, essa formação está presente, porém a grandes distâncias 
do rio. Suas características fundamentais já são bem conhecidas graças às contribuições de Freitas (1955 e 1964) e de Arid (1967). E constituída, predominantemente, por arenitos, intercalados por clásticos mais finos, siltitos e argilitos. Sua espessura, ao longo do rio, é variável, não ultrapassando $150 \mathrm{~m}$, assentando-se diretamente sobre os basaltos da Formação Serra Geral. Constitui sempre, na margem esquerda, os terraços mais elevados e mais distantes do rio. Em conseqüência, os perfis transversais do vale são sempre assimétricos, revelando diferenças de cotas acentuadas na margem paulista e muito mais suaves na margem oposta, de onde as rochas da Formação Bauru já foram removidas e substituídas pela Formação Rio Grande (Fig. 2).
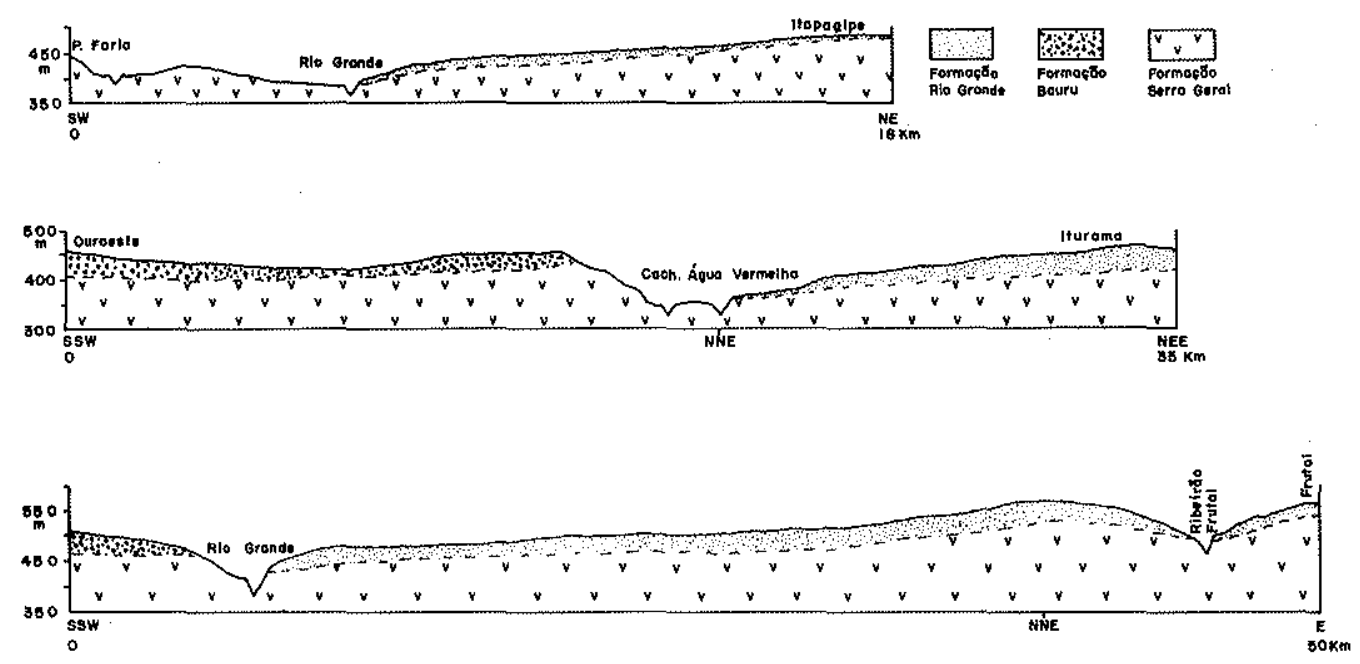

Figura 2 - Perfis geológicos (A) Paulo de Faria - Itapagipe; (B) Ouroeste - Iturama ; (C) Rio Grande - Frutal

FORMAÇÃO RIO GRANDE (Q) No lado mineiro, ocupando toda a margem direita, ocorre longa faixa de sedimentos neocenozóicos da Formação Rio Grande. Estende-se, com largura variável de até $50 \mathrm{~km}$, desde o curso médio até a confluência do Rio Paranaíba. Essa formação se assenta diretamente nos basaltos, próximo ao rio, e sobre a Formação Bauru à medida que dele se afasta, tendo sido proposta por Arid e Barcha (1971). Trata-se de um conjunto de sedimentos, dominantemente arenosos e intercalados por lentes de cascalho e argila, que se repetem na seqüência vertical, podendo atingir espessura de $50 \mathrm{~m}$. Os termos rudáceos constituem-se de conglomerado de seixos de tamanho variável, predominando seixos de diâmetro entre 8 a $16 \mathrm{~mm}$, podendo atingir até $20 \mathrm{~cm}$. Ocorrem, predominantemente, seixos de quartzito $(70 \%)$ e de quartzo $(29 \%)$, além de seixos de calcedônia, ágata e geodos de quartzo. Estudos de Arid e Barcha (op. cit.), mostraram que o arredondamento médio desses seixos é alto $(0,80)$, bem como são elevados os índices de esfericidade $(0,75)$. Esse conglomerado é, às vezes, muito consistente graças ao cimento silicoso ou limonítico. Nele são esculpidos os terraços mais elevados na margem direita, com inclinações suaves para o rio, situados, às vezes, dezenas de metros acima do nível atual das águas. Forma os depósitos de "monchões secos", portadores de diamantes detríticos, explorados nessa porção da bacia, por um grande número de garimpeiros. Atualmente essa formação está sendo intensamente retrabalhada pelo Rio Grande, dela procedendo grande parte dos sedimentos atuais. 
SEDIMENTOS ATUAIS Os sedimentos atuais são representados pelos depósitos que ocorrem no leito, nas margens rasas e nos locais de quebra da velocidade da corrente, tais como "praias" e nas áreas de cachoeiras e corredeiras. Esses depósitos são temporários, sendo o sedimento remobilizado na fase de enchente seguinte.

$\mathrm{Na}$ calha, os depósitos são constituídos por sedimentos arenosos, de textura variável, associados ou não a termos mais grosseiros, rudáceos. Nas zonas de quedas d'água ocorrem depósitos de grande variação granulométrica que se distribuem pelas margens do rio, logo após a linha de quedas, onde a competência sofre bruscas e profundas modificações. Permanecem, a maior parte do tempo, descobertos, sendo atuados pelas águas apenas nas épocas chuvosas. Como o rio corre, nessas áreas, encaixado no basalto, o aumento do volume de água não chega a inundar grandes trechos. Conseqüentemente, o rápido escoamento permite uma brusca flutuação da competência, imprimindo aos sedimentos aí depositados, feições granulométricas e texturais distintas.

As margens rasas e calmas localizam-se ao longo de estirões, onde a velocidade das águas é sempre baixa. São áreas baixas, de pequena profundidade, a qual aumenta gradativamente para o interior do rio. São recobertas pelas águas ou atıngidas pelas flutuações das ondas e pelas correntes oblíquas ou transversais. Essas correntes produzem, nos sedimentos aí depositados, marcas de onda.

As "praias" de enchente e barras estão acima das margens rasas e representam locais de maior competência, periodicamente atingidas pelas águas nas fases de maior pluviosidade. Esses sedimentos atuais foram amplamente estudados por Barcha (1973).

Aspectos morfológicos do perfil $\mathrm{O}$ perfil longitudinal do Rio Grande foi traçado com base em dados fornecidos pela Central Elétrica de Furnas S/A. Os autores expressam sua gratidão ao Dr. Rubens Vianna de Andrade, superintendente das obras da usina de Marimbondo, pelo fornecimento de dados. Trata-se de um perfil irregular, notável pelas rupturas de declive, principalmente no curso inferior, onde se localizam suas mais importantes quedas d'água e corredeiras (Fig. 3). Além das quebras locais, o perfil mostra um desnível acentuado em toda a sua extensão, ou seja, $1,3 \mathrm{~m} / \mathrm{km}$, em média. Contudo, em muitos trechos, o rio desce de modo mais abrupto. Da barragem da usina Mascarenhas de Moraes (Peixoto) até Jaguara, um percurso de $50 \mathrm{~km}$, o desnível é de $105 \mathrm{~m}$, com razão de $2,1 \mathrm{~m} / \mathrm{km}$; de Jaguara à confluência do Paranaíba, com desnível de $225 \mathrm{~m}$, a razão é de $2,5 \mathrm{~m} / \mathrm{km}$. Na área da Cachoeira do Marimbondo, em apenas $5 \mathrm{~km}$ de extensão, a descida é de $28 \mathrm{~m}$, com razão de $5,6 \mathrm{~m} / \mathrm{km}$.

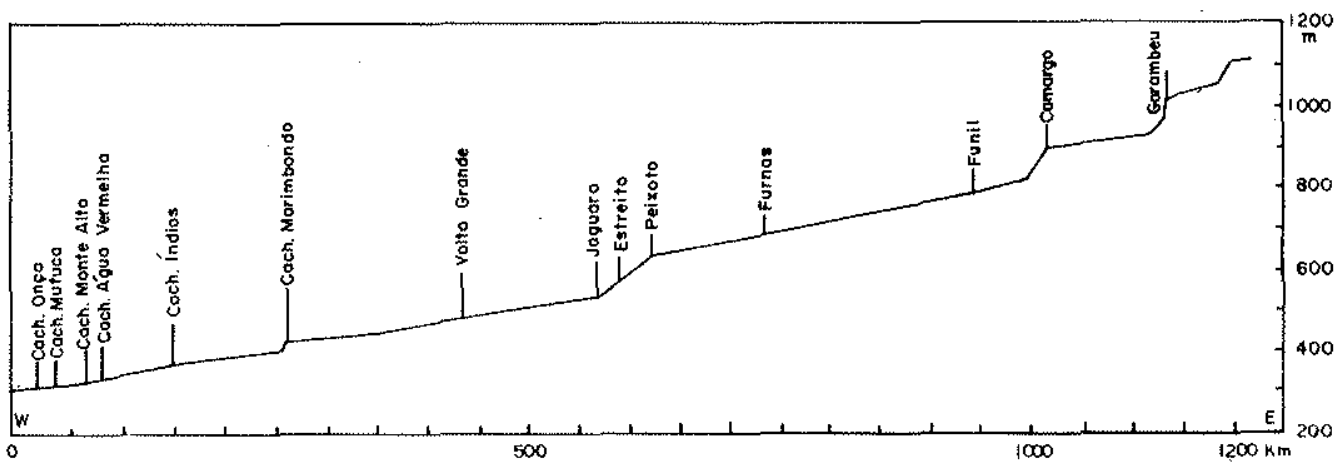

Figura 3 - Perfil longitudinal simplificado do Rio Grande mostrando a pronunciada declividade para oeste e as principais rupturas de declive. (Gentrais Elétricas de Furnas) 
No curso inferior, destacam-se as seguintes quebras do perfil e suas respectivas alturas:

$\begin{array}{lc}\text { Cachoeira do Marimbondo } & 28,0 \mathrm{~m}, \\ \text { Cachoeira dos fndios } & 0,8 \mathrm{~m}, \\ \text { Cachoeira da Água Vermelha } & 9,0 \mathrm{~m}, \\ \text { Cachoeira Monte Alto } & 0,8 \mathrm{~m}, \\ \text { Cachoeira Mutuca } & 1,0 \mathrm{~m}, \\ \text { Cachoeira da Onça } & 8,0 \mathrm{~m} .\end{array}$

E importante assinalar que, não obstante a maturidade do relevo no curso inferior, é justamente nesse trecho que* o Rio Grande apresenta o perfil mais acidentado, com algumas de suas quedas figurando entre as principais do Brasil: Marimbondo ( $350 \mathrm{mil} \mathrm{cv}) \mathrm{e}$ Água Vermelha $(130 \mathrm{mil} \mathrm{cv})$. As demais citadas somam potencial hidráulico acima de 5 mil cv (CIBPU, 1955).

A análise do perfil mostra ainda que o Rio Grande é uma corrente dominantemente fixa. Ocorrem, porém, pequenos trechos de canal subdividido, condicionando, em larga escala, um processo erosivo vertical maior que o lateral, aprofundando o leito do rio de ano para ano. A erosão aí atuante leva à formação de trechos estreitos, com águas violentas, seguidos de estirőes mais calmos, onde o rio é mais largo. Nos trechos onde as águas são violentas, o rio chegou a encaixar seu leito mais de uma centena de metros. Terraços sucessivos foram abandonados, tendo sido os mais antigos construídos, a maior distância, em sedimentos da Formação Bauru e na Formação Rio Grande, e os mais recentes esculpidos nos basaltos. $\mathrm{O}$ desenvolvimento de canyons é outra conseqüência desse encaixamento. Exemplos típicos ocorrem na área da Cachoeira do Marimbondo e da Água Vermelha.

Durante os períodos sucessivos de enchente e vazante, a seç̧ão transversal molhada modifica-se bastante, embora se mantenha a posição do canal, ou, então, se se modifica, faz isso lentamente. Essa mudança se deve, provavelmente, ao fato de a descarga ser mais rápida do que os processos de remodelação morfológica do canal e à resistência das rochas do substrato.

Quedas d'água ASPECTOS MORFOLÓGICOS E GEOLÓGICOS Em geral, em todas as quedas estudadas, o rio é bastante largo, calmo e raso a montante, com profundidades não superiores a $3 \mathrm{~m}$ (Fig. 4). Esculpidas sempre nos basaltos, são compostas de grupos complexos de quedas e corredeiras que se estendem por até $4 \mathrm{~km}$, e apresentam altura total de $30 \mathrm{~m}$, como ocorre na Gachoeira do Marimbondo (Foto 1). Após as frentes de quedas, o rio se divide em dois braços, o mineiro e o paulista, sendo sempre mais expressivas as quedas e os canais do lado mineiro. Em Marimbondo, as quedas do lado paulista,

Foto 1 - Gachoeira do Marimbondo. Vista parcial dos Patos (Patos Mineiro)

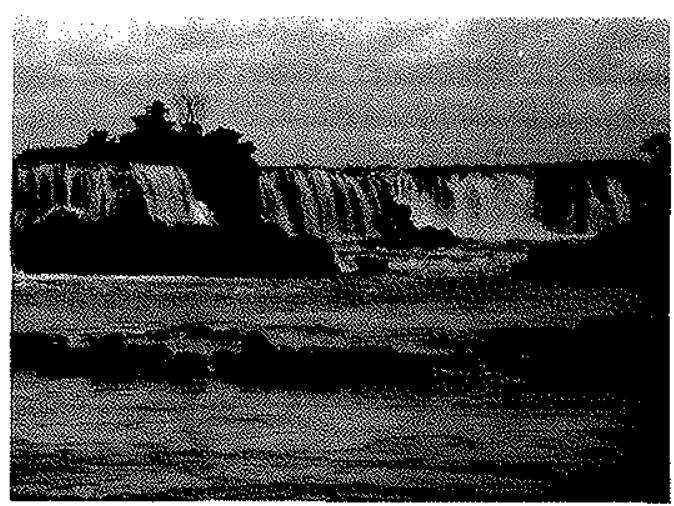


denominadas Patos Paulista, possuem altura de $6 \mathrm{~m}$, enquanto que, na margem oposta, Patos Mineiro, possuem altura de $10 \mathrm{~m}$. Na Cachoeira da Agua Vermelha, a frente principal de quedas está, também, no lado mineiro, com altura de $9 \mathrm{~m}$ (Foto 2). Diminui para o lado paulista até uma altura de $50 \mathrm{~cm}$. Na Cachoeira da Onça, o fato se repete. A linha de quedas, na margem paulista, é apenas uma corredeira e atinge um máximo de $8 \mathrm{~m}$ no lado mineiro, cortando o rio diagonalmente (Foto 3 ).

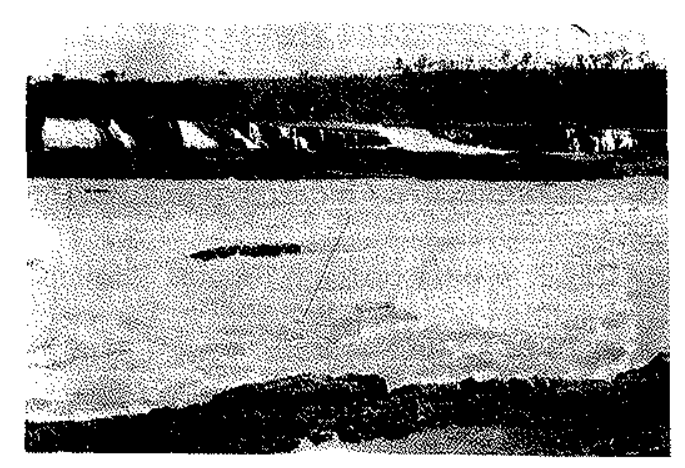

Foto 2 - Cachoeira da Agua Vermelha. Vista parcial das quedas principais, situadas no lado mineiro, mostrando o controle por grandes diáclases recurvadas

Foto 3 - Cachoeira da Onça. Vista parcial, a grande distância, das quedas principais, situadas no lado mineiro

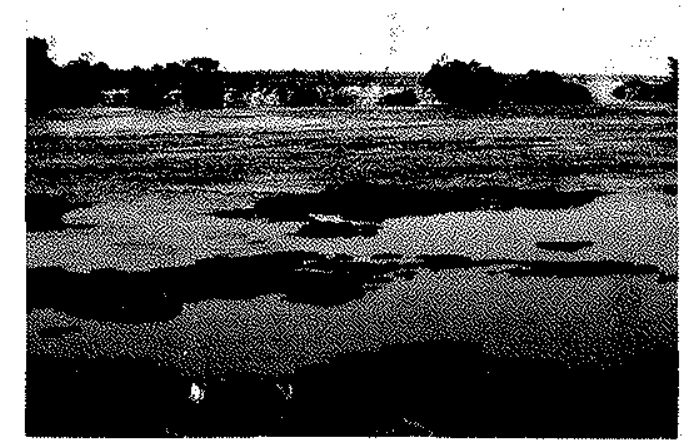

Encaixado no basalto, o rio desenvolve suas quedas no contato dos derrames, estando ou não presentes lentes de arenito intratrapiano e brechas de basalto. Observa-se também a diferente resistência que as porções microcristalina e amigdalóide dos derrames oferecem à erosão. Sendo mais rapidamente decomposta, a fase amigdalóide permite à água remover, por solapamento, grandes blocos de basalto microcristalino do derrame superior, densamente diaclasado. $\mathrm{O}$ mesmo fenômeno ocorre quando massas de lava consolidadas possuem na base intenso diaclasamento horizontal. Na Gachoeira da Onça, na base das quedas, o basalto, com intenso diaclasamento horizontal, é mais intemperizado, permitindo fácil remoção de blocos superiores com fraturas verticais. $\mathrm{Na}$ Cachoeira do Marimbondo, a rapidez da decomposição do basalto amigdalóide, o intenso fraturamento horizontal e vertical e, ainda, a presença de arenito intratrapiano no contato determinam a mesma conseqüuência.

A existência de sistemas preferenciais de fraturas no basalto faz com que a frente de quedas seja constituída por uma sucessão de pequenos degraus salientes, resultantes da ação das águas que desalojam blocos de basalto, atuando poderosamente em suas fraturas. Enormes diáclases recurvadas, separando massas lenticulares de rochas, foram anotadas 


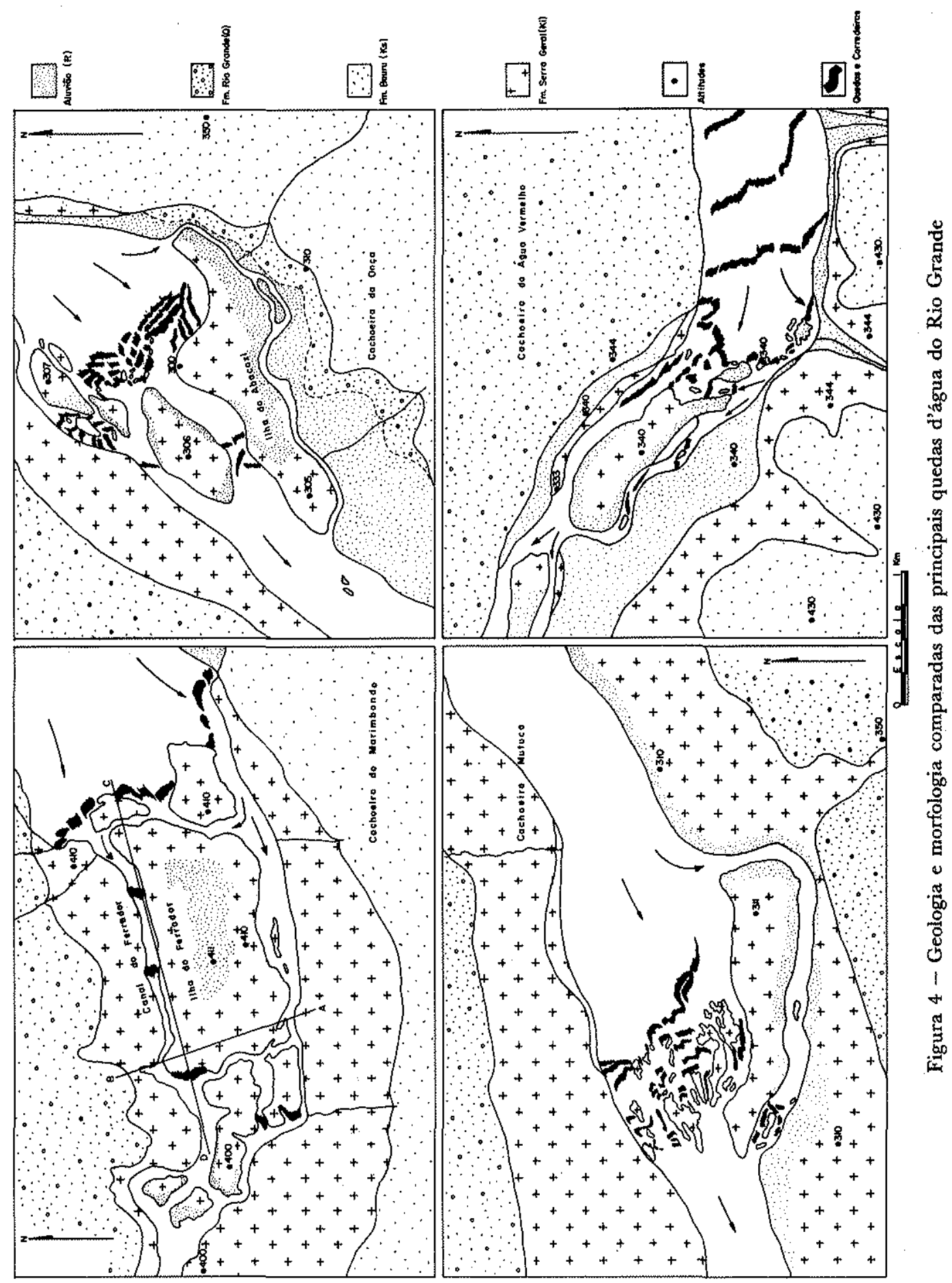


pela primeira vez por Pacheco (1913) na Cachoeira da Água Vermelhạ. Ocorrem também no Salto das Andorinhas, na Cachoeira do Marimbondo; sob a ação das águas, provocam a formação de verdadeiros degraus de até $4 \mathrm{~m}$ de altura. Toda a frente de quedas na Cachoeira da Água Vermelha é constituída por esses degraus.

Formam-se dois ou mais canais imediatamente após as quedas, os quais, por sua vez, se unem para formar um único, bem mais estreito, mais profundo e encaixado, com terraços esculpidos diretamente nos basaltos. Formam-se, conseqüentemente, várias ilhas, sendo as menores recobertas pelas águas no período de enchente.

O canal principal está situado sempre do lado mineiro, por onde escoa o maior volume de água ( $\pm 70 \%$ ). Nas cachoeiras do Marimbondo e da Água Vermelha, esse canal principal, que possui cotas inferiores ao canal secundário, ou paulista, escoa a água com violência indescritível, capaz de erodir o leito de maneira extraordinária (Foto 4), formando

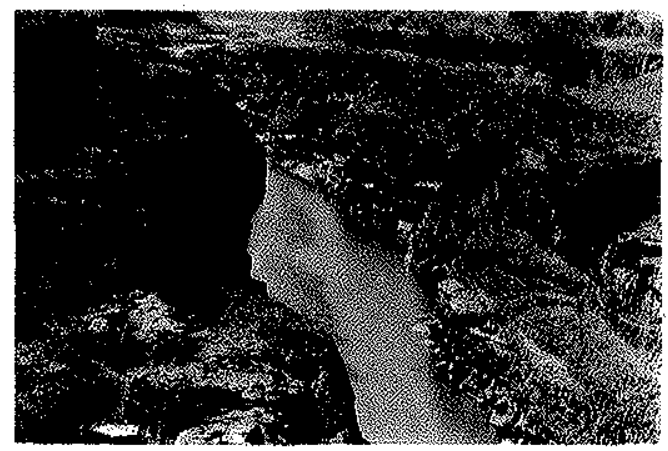

Foto 4 - Cachoeira do Marimbondo, Canal do Ferrador. Vista parcial do canal após o desvio das águas do Rio Grande. Nota-se o encaixamento profundo do leito e a sucessão de terraços

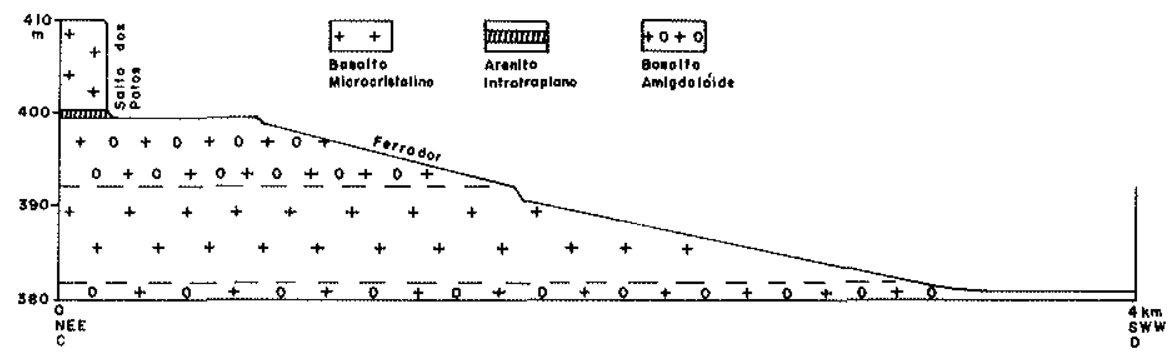

Figura 5 - Perfil geológico esquemático da Cachoeira do Marimbondo

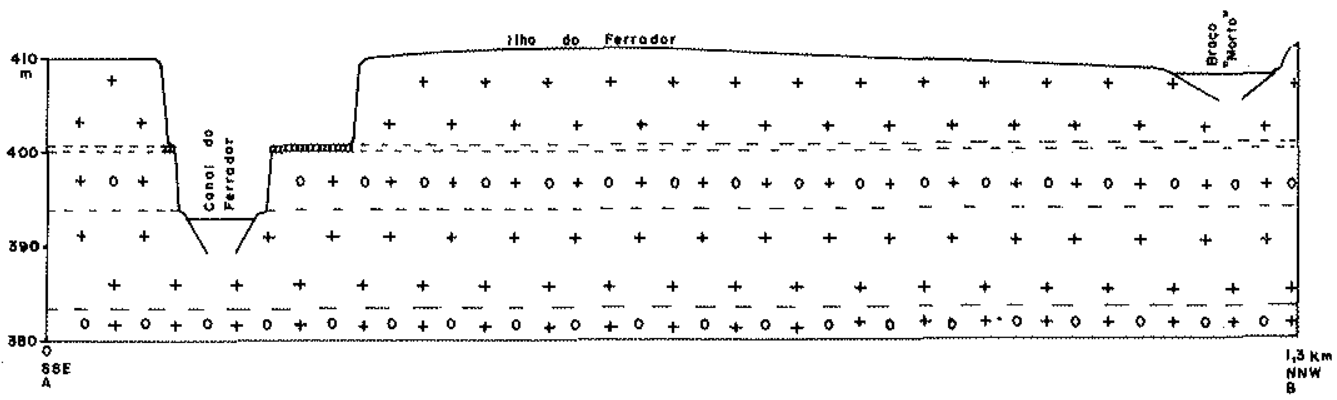

Figura 6 - Perfil geológico esquemático da Ilha do Ferrador 
canyons profundos e estreitos. Na Cachoeira do Marimbondo, o canyon conhecido como Canal do Ferrador (Foto 4) possui, no trecho final, uma largura média de $20 \mathrm{~m}$ e uma profundidade de $50 \mathrm{~m}$, tomando-se como referência o nível das águas no Salto dos Patos antes das quedas (Fig. 5). Comparando-se seu trecho final com o trecho correspondente do canal secundário, denominado Braço Morto, verifica-se um desnível de $18 \mathrm{~m}$ (Fig. 6).

Situado no lado paulista, o canal secundário possui características morfológicas e fluviométricas diversas às do canal principal. Por ele flui sempre menor quantidade de água ( $\pm 30 \%$ ), é mais largo, mais raso, de ação erosiva muito menor e está situado em plano mais elevado. No trecho de confluência com o canal principal, verificam-se quedas de menor expressão ou corredeiras. Na Cachoeira da Onça, nas proximidades de Santa Fé do Sul, e na Cachoeira Mutuca, nas proximidades de Santa Albertina, esse canal secun* dário inicia antes da linha de quedas e, contornando a cachoeira, vai se unir ao canal principal algumas centenas de metros abaixo. Nas cachoeiras do Marimbondo e da Água Vermelha, o canal secundário tem origem na base da linha de quedas. É um canal através do qual também flui menor volume de água que o principal e, como nos casos anteriores, apresenta cotas sempre maiores. Isso explica a diferença de volume de água que escoa, responsável pela notável intensidade erosiva que se registra no canal principal.
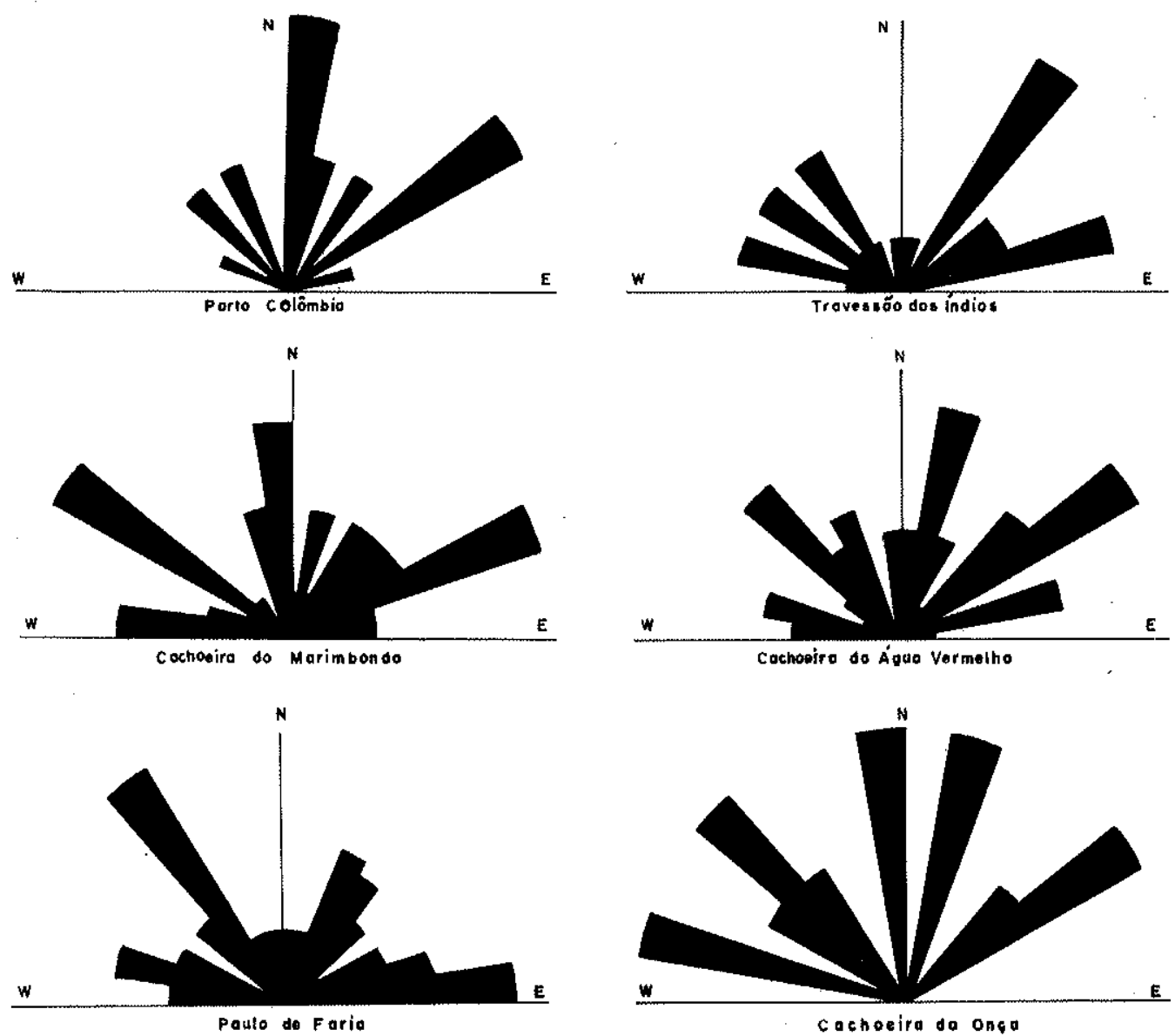

Figura 7 - Sistemas preferenciais de fraturas do basalto ao longo do Rio Grande 
A direção geral das quedas apresenta valores bastante aproximados nas cachoeiras estudadas. Na Cachoeira da Onça, predomina N30-40W; na Cachoeira da Água Vermelha, N50-60E e N40-50W; na Cachoeira do Marimbondo, N30E, N30W e EW. Em razão do pronunciado encaixamento do rio, a juzante das quedas, os pequenos tributários que aí vêm desaguar possuem vales profundos, de paredes íngremes, em forma de $\mathrm{V}$ bem fechado, isolando espigões de superficies aplainadas, com cotas superiores às do nível das águas em até uma centena de metros. A direção principal desses afluentes, cujo trecho final corta também os basaltos, concorda ou está muito próxima das direções das quedas, como apontaram Arid e Landim (1967), Arid e Barcha (1971), para a área da Cachoeira do Marim. bondo.

Em seis locais diferentes, no curso inferior do Rio Grande, incluindo as áreas de quedas, foram efetuadas medidas de direção das fraturas do basalto: Porto Colômbia, Cachoeira do Marimbondo, Paulo de Faria, Cachoeira (Travessão) dos Índios, Cachoeira da Água Vermelha e Cachoeira da Onça. As leituras, reunidas em classes de $10^{\circ}$ e lançadas em gráfico (Fig. 7), permitiram estabelecer sistemas preferenciais de fraturas.

$\begin{array}{cc}\text { Porto Colômbia } & \text { Cachoeira do Marimbondo } \\ \text { N50-60E } & \text { N60-70E } \\ \text { N20-30W } & \text { N50-60W } \\ \text { N40-50W } & \text { NS } \\ \text { NS } & \text { EW } \\ \text { Paulo de Faria } & \text { Cachoeira (Travessão) dos fndios } \\ \text { N20-30E } & \text { N30-40E } \\ \text { N30-40W } & \text { N30-40W } \\ \text { EW } & \text { N50-60W } \\ & \text { N70-80E } \\ & \text { N70-80W } \\ \text { Cachoeira da Agua Vermelha } & \text { Cachoeira da Onça } \\ \text { N50-60E } & \text { N50-60E } \\ \text { N50-60W } & \text { N40-50W } \\ & \text { NS }\end{array}$

Embora tenham sido tratadas em classes de $10^{\circ}$, a distribuição gráfica das medidas recomendou, para melhor análise dos resultados, a reunião das leituras em classes mais amplas. Dessa forma, as zonas mais significativas, tomadas de 20 em $20^{\circ}$ são:

$$
\begin{array}{lr}
\text { N10-30E } & \text { N40-60W } \\
\text { N50-70E } & \text { N70-90W }
\end{array}
$$

Quando se comparam os sistemas preferenciais de fraturas com as direções preferenciais das quedas d'água, nota-se uma estreita correspondência entre eles, em todas as quedas estudadas, sugerindo que as fraturas têm marcante influência no controle das quedas. Verifica-se também que existe a mesma correspondência entre os canyons na Cachoeira do Marimbondo (EW) e na Cachoeira da Agua Vermelha (N40-50W), com os mesmos sistemas de fraturas.

CONCLUSÓES ORIGEM E EVOLUĢÃO DAS QUEDAS O perfil longitudinal do Rio Grande mostra a existência de numerosas e importantes quebras, representadas por corredeiras e cachoeiras. Ocorrem sempre no basalto, não ultrapassando $10 \mathrm{~m}$ de altura. 
As principais frentes de quedas têm as mesmas direções dos sistemas de fraturas do basalto, sugerindo íntima relação entre elas. Além disso, lentes de arenito intratrapiano (Foto 5), brechas de basalto (Foto 6) e diferente textura litológica denunciam idêntica relação.

Em vista disso, todas elas evoluem da mesma forma. Blocos de basalto compacto, microcristalino, separados por diáclases, são removidos pela corrente quando a erosão, mais acentuada na base, destrói o basalto amigdalóide, a lente de sedimento ou o basalto fraturado horizontalmente que aí ocorram. Dessa forma, ao regredir, a linha de quedas mantém a mesma altura (Fotos 7 e 8 ).

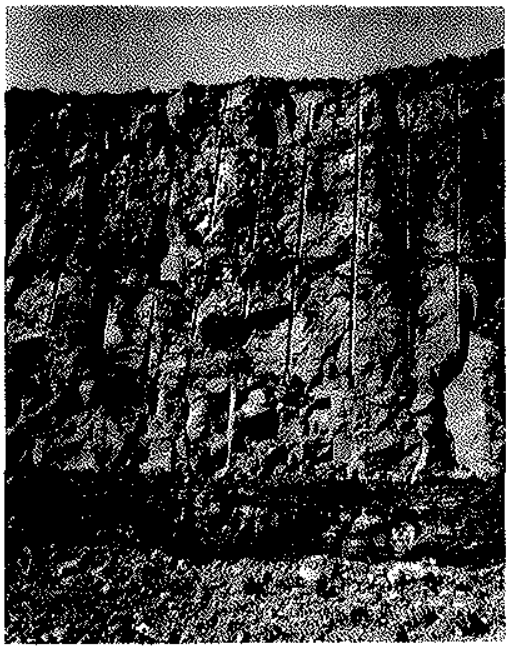

Foto 5 - Cachoeira do Marimbondo. Vista parcial de um derrame de basalto, apresentando na base lente de arenito intratrapiano

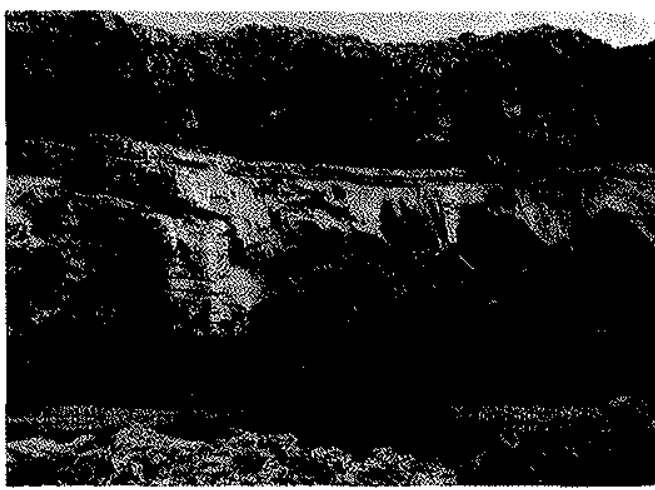

Foto 7 - Cachoeira do Marimbondo, Salto das Andorinhas. Vista parcial, de frente, do principal salto do Braço Morto, mostrando os efeitos do complexo mecanismo de evolução das quedas do Rio Grande

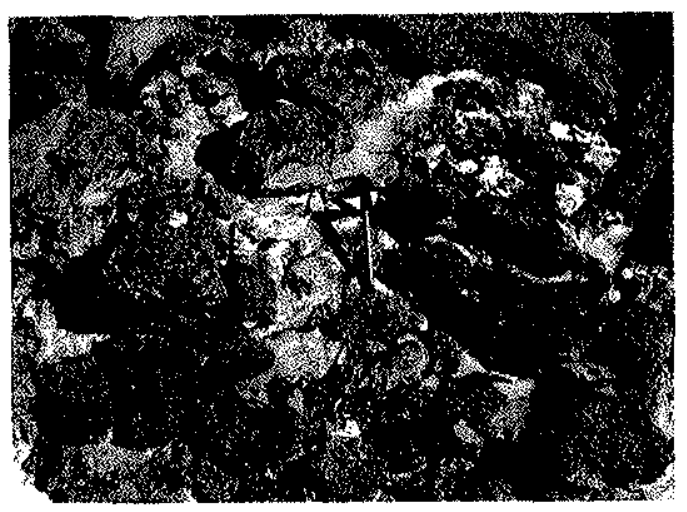

Foto 6 - Cachoeira do Marimbondo. Brecha de basalto presente no Braço Morto

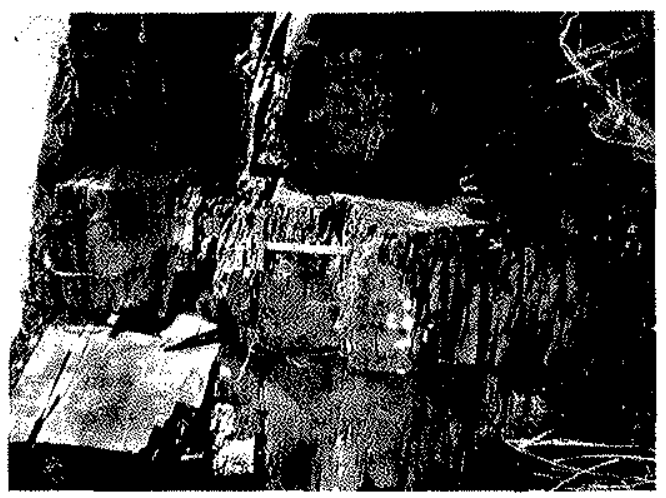

Foto 8 - Cachoeira da Onça. Basaltos profundamente diaclasados, horizontal e verticalmente, feições importantes do controle estrutural e evolução das quedas 
A presença constante desses fatores revela a mesma origem para todas as quedas do Rio Grande. Pacheco (1913, p. 34) chamou a atenção, pela primeira vez, para as principais feições dos saltos e cachoeiras dos rios Grande e Turvo, atribuindo-as aos sistemas de juntas. Washburne (1930, pp. 112-113) relacionou as quedas da bacia do alto Paraná a estruturas monoclinais no basalto. A origem dessas quedas tem sido também atribuída a falhamentos (Moraes Rego, 1932; Gutmans, 1949; Loczy, 1966).

Estudos realizados por Ruiz (1963), com base em sondagens na área de Jupiá, no Rio Paraná, em Barra Bonita, no Rio Tietê e na Cachoeira Dourada, no Rio Paranaíba, não indicaram a existência de falhas. Analisando perfis de sondagens realizadas pela CEMIG na área da Cachoeira do Marimbondo, Arid e Landim (1967) não constataram a presença de falhamento, vinculando sua origem ao vigoroso sistema de fraturas presentes no leito basáltico, e à ação erosiva das águas do rio. Estudos efetuados por Björnberg et al. (1972) sobre a tectônica moderna no Estado de São Paulo sugerem que poderia haver a possibilidade de influência de falhamentos de pequena escala na origem dessas quedas.

Os estudos de campo parecem mostrar que, em todas, o Rio Grande, ao atingir o basalto, encontrou uma superficie irregular e, graças aos fatores mencionados, pôde construir as quedas de seu perfil.

A origem e a evolução das quedas estão ligadas, como apontaram Arid e Landim (op. cit.), seguramente, ao sistema de fraturas presentes no leito basáltico, rompido pela retomada de erosão que ainda se processa atualmente. Apesar de não termos encontrado, no campo, evidências de falhamento, o reajustamento isostático que se verifica nos cursos médio e inferior do rio poderia, contudo, provocar pequenos deslocamentos de fraturas dando origem a falhamento que, eventualmente, poderiam originar essas quedas. As quedas, canyons, estreitos e profundos, a sucessão de terraços, o encaixamento do rio no substrato basáltico e o retrabalhamento dos depósitos quaternários da margem mineira, indicam que o processo ainda está em pleno desenvolvimento.

A similaridade observada das feições morfológicas e estruturais, nas demais cachoeiras da bacia do alto Paraná, sugere idênticos processos na origem e evolução de todas as quedas dessa bacia.

GONTROLE ESTRUTURAL E EVOLUÇÃO DA DRENAGEM Controle estrutural A partir do ponto em que abandona o maciço cristalino para correr definitiva. mente encaixado no basalto, o Rio Grande apresenta um rumo geral quase W. Com base nas cotas do topo do basalto, tomadas em afloramentos e em poços semi-artesianos (Fig. 8) verifica-se que a calha do rio segue uma pendente para $W$, apesar de o mergulho regional do substrato basáltico orientar-se para SW (Frangipani, 1961-62). A direção, contudo, parece estar controlada direta ou indiretamente pelas estruturas do basalto. Por outro lado, quando se consideram a direção geral do Rio Grande e as quebras locais dessa direção, verifica-se que seus valores concordam com a direção dos principais sistemas de fraturas determinadas nessas áreas. Idêntica conformação ocorre em relação aos tributários do rio, nesses locais, levando-se em conta os trechos finais, igualmente encaixados no basalto.

Arid e Landim ( $o p . c i t$.) e Arid e Barcha ( $o p . c i t$.) apontaram a influência dessas fraturas no controle da drenagem na área da Cachoeira do Marimbondo. Os estudos realizados ao longo de todo o trajeto revelam vigorosa influência do sistema de fraturas nos cursos médio e inferior do Rio Grande, resultando disso, a nosso ver, não apenas as mudanças locais de direção, mas também a própria direção geral do Rio Grande (Fig. 9).

Fixaçâo do curso atual do Rio Grande O Rio Grande é hoje parte de um sistema hidrográfico centrípeto, onde os rios acompanham, em geral, o pequeno mergulho das camadas sedi- 


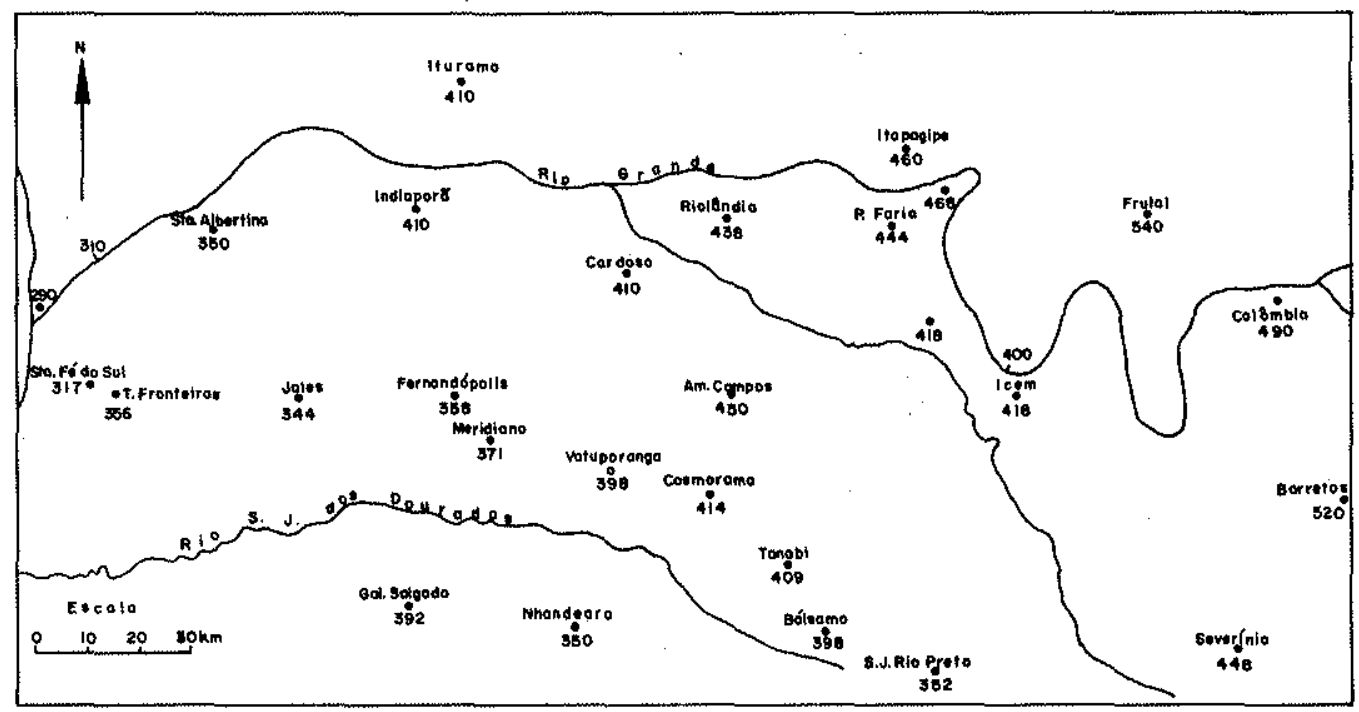

Figura 8 - Cotas do basalto ao longo do baixo Rio Grande mostrando pendente para W, porém com mergulho regional para $\mathrm{SW}$

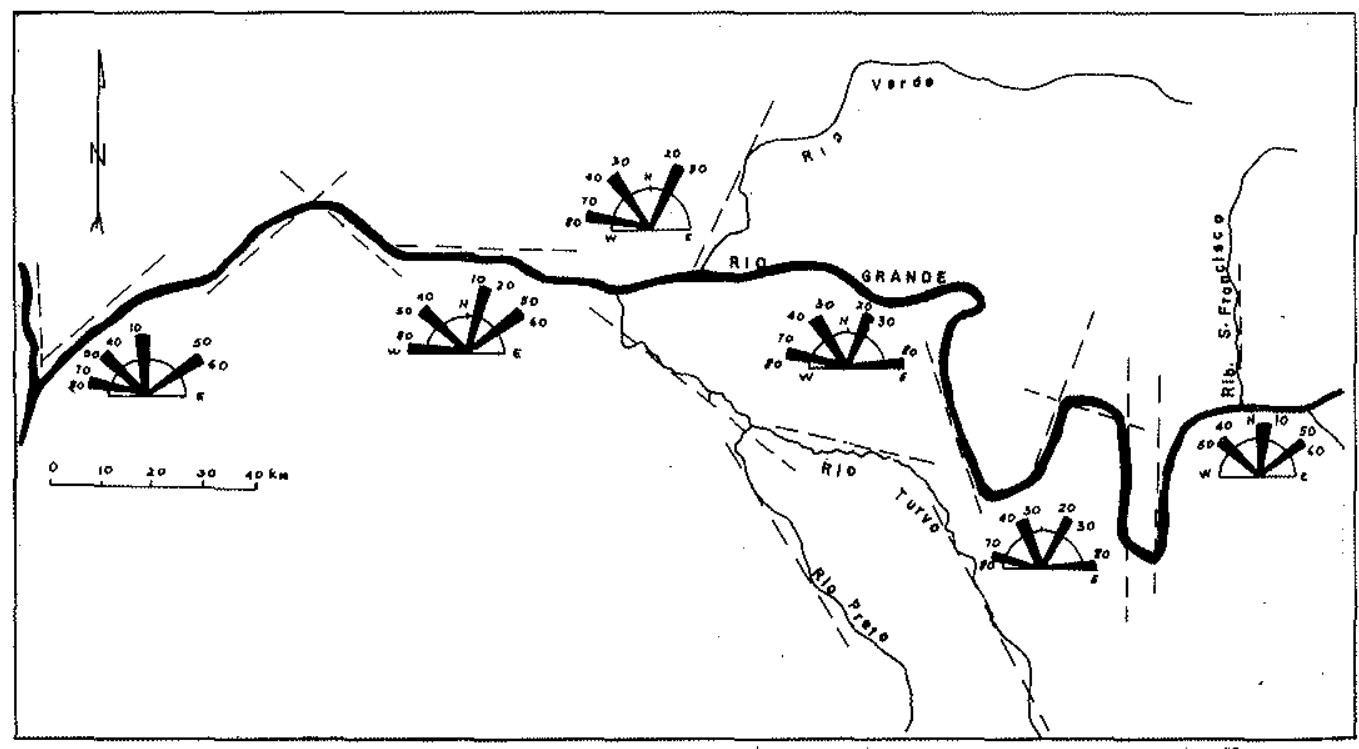

Figura 9 - Principais quebras de direção no curso inferior do Rio Grande e afluentes, e suas relações com os principais sistemas de fraturas do basalto

mentares, cujos valores diminuem da periferia para o centro até quase uma horizontalidade nas camadas da Formação Bauru (Gutmans, 1949, p. 47; Almeida, 1956, p. 22; 1968, p. 94; Ab'Saber, 1968, p. 177).

É provável que a drenagem do alto Paraná até o fím do Pleistoceno não tenha sido muito diferente da atual, dirigindo-se para oeste ou sudoeste (Moraes Rego, 1932). Almeida (1956, p. 24) refere-se à presença de seixos de granito, quartzito e turmalinito nas rochas da Formação Bauru e que, vindos de fora da bacia, indicariam uma drenagem radial 
centrípeta em busca de um antigo coletor, predecessor do Rio Paraná. Arid (1967), através de estudos de paleocorrentes, sugere drenagem neocretácea orientada para $W$, predominantemente SW, na região norte-ocidental do Estado de São Paulo. Arid e Barcha (1971), estudando a Formação Rio Grande, constataram, na área da Gachoeira do Marimbondo, pelo embricamento de seixos, que a direção da paleocorrente, imediatamente anterior à atual, dela não diferia muito.

Com o levantamento do Planalto Atlântico em relação à bacia do alto Paraná (Almeida, 1964, p. 258), os rios puderam embutir seus vales na superficie sedimentar neocretácea, até o basalto, através de um processo de retomada de erosão vigorosa. Com isso, o predecessor do Rio Grande, ou ele mesmo, cortando o capeamento sedimentar neocenozóico e neocretáceo, pôde fixar seu curso definitivamente no basalto, graças ao controle das estruturas aí encontradas. Cachoeiras, corredeiras, canyons, caracterizam hoje o Rio Grande como um rio rejuvenescido. Os sedimentos fluviais da Formaçåo Rio Grande representam um episódio anterior, diverso do atual. A sucessão contínua de terraços esculpidos no substrato basáltico revela que, ainda hoje, o rio continua evoluindo, aprofundando seu leito.

A idade da Formação Rio Grande foi atribuída ao fecho do Pleistoceno, podendo alcançar até o Holoceno inferior (Arid e Barcha, 1971). Segundo Washburne (1930), a rapidez da erosão e a velocidade das águas nas áreas de quedas demonstram um rejuvenescimento recente, de acordo com Ab'Saber (1969), a partir do Quaternário.

Conseqüentemente, a fixação definitiva da atual drenagem comandada pelo Rio Grande e, provavelmente, da bacia do alto Paraná não vão além do Holoceno inferior.

Agradecimentos $\mathrm{O}_{\mathrm{s}}$ autores agradecem as críticas e sugestðes apresentadas pelo professor Dr. Josué Camargo Mendes, professor Dr. Setembrino Petri e professor Dr. Celso Barros Gomes, do Instituto de Geociências da USP, e pelo professor Dr. Paulo Milton Barbosa Landim, da FFCL de Rio Claro.

\section{BIBLIOGRAFIA}

Ab'SABER, A. N. - 1969 - Ritmo da epirogênese pós-cretácica e setores das superficies neogênicas em São Paulo. Geomorfologia, 13, Inst. Geogr. Univ. de São Paulo

ALMEIDA, F. F. M. - 1956 - O planalto basáltico da bacia do Paraná. Bol. Paul. Geogr., 24: 3-34, São Paulo

ALMEIDA, F. F. M. - 1964 - Fundamentos geológicos do relevo paulista Bol. 41 : 169-263. Geologia do Estado de São Paulo, Inst. Geog. Geol., São Paulo

ARID, F. M. - 1967 - A Formação Bauru na região norte-ocidental do Estado de São Paulo. Tese de doutoramento apresentada à Fac. Fil. Giênc. e Letras de S. J. do Rio Preto, São Paulo

ARID, F. M. e LANDIM, P. M. B. - 1967 - Contribuição ao estudo da Geologia da Cachoeira do Marimbondo (Rio Grande). Bol. Soc. Bras. Geol. 16 (2): 39-59

ARID, F. M. e BARCHA, S. F. - 1971 - Sedimentos neocenoz6icos no vale do Rio Grande Formação Rio Grande. Sedimentologia e Pedologia (2), Inst. de Geogr. da Univ. de São Paulo

BARBOSA, O. - 1957 - Observaçð̃es e comparaçð̃es sobre algumas ocorrências vulcânicas no Peru, no México e no Brasil. DNPM, Div. Geol. Min. Bol. 167: 43

BARCHA, S. F. - 1973 - Sedimentos recentes no vale do Rio Grande. Tese de doutoramento apresentada à Fac. de Fil. Giênc. e Letras de S. J. do Rio Preto, Săo Paulo

BJÖRNBERG, A.J.S., GANDOLFI, N. e PARAGUASSU, A. B. - 1972 - Investigações sobre tensões residuais em magmatitos básicos. Ciênc. Cult. Resumos XXIV Reunião anual, S. B. P. C.

GIBPU - 1955 - Condiçð̃es geográficas e aspectos geoeconômicos da bacia do Paraná-Uruguai, II, São Paulo

FLORENCE, G. - 1907 - Notas geológicas sobre o Rio Tietê, in Exploração do 'Tietê - Folio, Comm. Geogr. Geol. p. 12-13, São Paulo 
FRANGIPANI, A. - 1961.62 - Mapa da superficie superior do basalto subjacente aos arenitos cretáceos do Estado de São Paulo. Rev. I. G. G., anos XVIII e XIX, n. ${ }^{\circ}$ único, pp. 67-72, São Paulo

FREITAS, R.O. - 1955 - Sedimentação, estratigrafia e tectónica da Série Bauru (Estado de São Paulo). Fac. Fil. Ciênc. Letras da USP, Geol. 14 (194), São Paulo

FREITAS, R. O. - 1964 - Grupo Bauru. Geologia do Estado de São Paulo. I. G. G., Bol. 41: 126-147

GUTMANS, M. - 1949 - Tectônica da bacia do Paraná. Rev. Mineração e Metalurgia, XIV (80): $47-50$

LAMEGO, A. R. - 1935 - Contribuição à Geologia do vale do Rio Grande, Minas Gerais. Min. Agr., Serv. Geol. Min., Bol. 70, Rio de Janeiro

LEINZ, V. - 1949 - Contribuição à Geologia dos derrames basálticos do sul do Brasil. Bol. da Fac. de Fil., Ciênc. e Letras da Univ. de São Paulo, (CIII), Geol. 5: 61

LOCZY, L. - 1966 - Evolução paleogeográfica e geotectônica da bacia gondwânica do Paraná e de seu embasamento. D. N. P. M., D.G.M., Bol. 234, Rio de Janeiro

PACHECO, J. A. A. - 1913 - Notas sobre a Geologia no vale do Rio Grande a partir da foz do Rio Pardo até a confluência com o Rio Paranaíba - Exploração do Rio Grande e seus afluentes. Gomm. Geogr. Geol. pp. 33-39, São Paulo

PICHLER, E. - 1952 - Diques de arenito em Salto Grande, Rio Paranapanema. Bol. Soc. Bras. Geol. 1 (1): $15-22$

PUTZER, H. - 1954 - Die Wasserfälle des Rio Iguaçu (Brasilien) und ihre tektonischen Uroachen. Natur. und Volk, 84, pp. 388-395

REGO, L. F. M. - 1932 - Notas sobre a geomorfologia de São Paulo e sua gênese. Inst. Astron. e Geogr., São Paulo

RUIZ, M. D. - 1963 - Geologia aplicada à barragem de Jupiá (sistema Urubupungá). Inst. Pesq. Tecnol. da Univ. de São Paulo, Celusa

WASHBURNE, C. W. - 1930 - Petroleum Geology of the State of São Paulo. Comm. Geogr. Geol. Bol., 22, São Paulo 